\title{
Chapter 1 \\ The Spread of the Application \\ of the Microwave Technique in Organic \\ Synthesis
}

\author{
Erika Bálint and György Keglevich
}

\begin{abstract}
The first chapter summarizes the birth and spread of the application of the microwave (MW) technique in organic syntheses placing the stress on the development of the MW equipment. These days professional batch and continuous flow reactors are available, and the application is knocking at the door of industry.
\end{abstract}

Keywords Microwave $\cdot$ Batch reactors $\cdot$ Continuous reactors

These days, the protection of our environment and our health is becoming increasingly important due to the worldwide spread of green chemistry. According to the 12 principles of green chemistry [1], preparation and development of environmentally-friendly and harmless products and technologies are the main tasks. In this context, the application of the microwave (MW) technique in organic, inorganic, medicinal, analytical and polymer chemistry has spread fast [2-8].

The first domestic microwave oven was introduced by at the end of 1955, but the widespread use of these ovens in households occurred during the 1970s and 1980s. From the middle of 1970s, engineers and researchers started to apply the MW technique in food processing, in the drying industry, in waste remediation and in analytical chemistry. In the latter case, this technique has been used for sample preparation (e.g. digestion, extraction, dissolution, etc.) [9-12]. The first application of microwave irradiation in chemical synthesis was published in 1986 by the groups of Gedye and Giguere $[13,14]$. Since then, the number of publications in this field has sharply increased (Fig. 1.1). Most of these publications describe important acceleration of a wide range of organic chemical reactions, excellent repro-

\footnotetext{
E. Bálint $(\bowtie)$

MTA-BME Research Group for Organic Chemical Technology,

1521 Budapest, Hungary

e-mail: ebalint@mail.bme.hu

G. Keglevich

Department of Organic Chemistry and Technology, Budapest University

of Technology and Economics, 1521 Budapest, Hungary

(C) Springer International Publishing Switzerland 2016

G. Keglevich (ed.), Milestones in Microwave Chemistry, SpringerBriefs in Green Chemistry for Sustainability,

DOI 10.1007/978-3-319-30632-2_1
} 


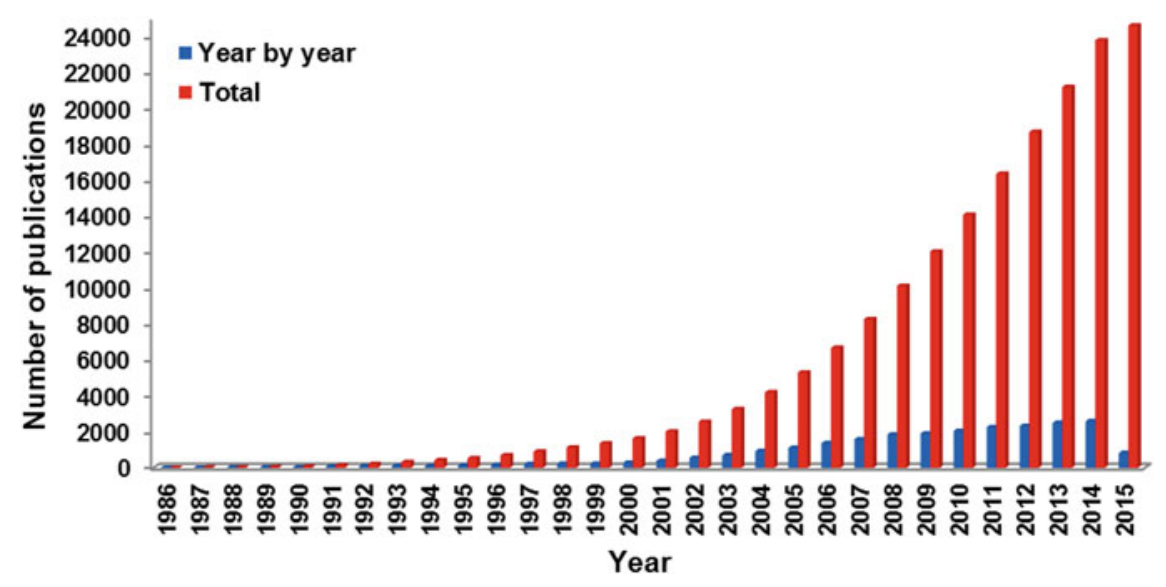

Fig. 1.1 The number of publication on MW-assisted synthesis (1986-2015). Web of Science keyword search on "microwave synthesis"

ducibility, improved yields and less side reactions compared to conventional heating.

Early pioneering experiments were performed in domestic MW ovens, where the irradiation power was controlled generally by on-off cycles of the magnetron, and it was not possible to monitor the inner temperature in a reliable way, thus the reactions were not reproducible. The other problems were on the safety issues of such experiments [15-17]. From the early 2000s, dedicated MW instruments started appearing in market, which are indeed suitable for performing chemical reactions under controlled conditions [2, 3, 18]. All commercially available dedicated MW reactors consist of a MW cavity, magnetic stirrer, sensor probe (IR sensor or fiber optic probe), and software that enables on-line temperature/pressure control by regulating the MW power output.

The MW instruments are classified in two types, monomode (single mode) and multimode MW reactors. The main difference between the two systems is that while in monomode reactors only one reaction vessel can be irradiated, multimode reactors may accommodate several vessels simultaneously.

A monomode instrument has a small compact cavity, where the microwave energy is generated by a single magnetron, and directed through a rectangular waveguide to the reaction mixture, which is positioned at a maximized energy point (Fig. 1.2). A highly homogenous energy field of high power intensity is provided, resulting in exceedingly fast heating rates.

In addition, monomode instruments with a self-tuning circular waveguide are also available (Fig. 1.3). This cavity features multiple entry points for introducing the microwave energy into the vessel.

Multimode reactors have larger cavities, in which the microwaves are reflected from the cavity walls, and distributed in a rather chaotic manner (Fig. 1.4). The reaction vessels are continuously rotated within the cavity, to provide a steady 
Fig. 1.2 The microwave field distribution in a monomode reactor [3]

Fig. 1.3 Circular single-mode cavity [2]
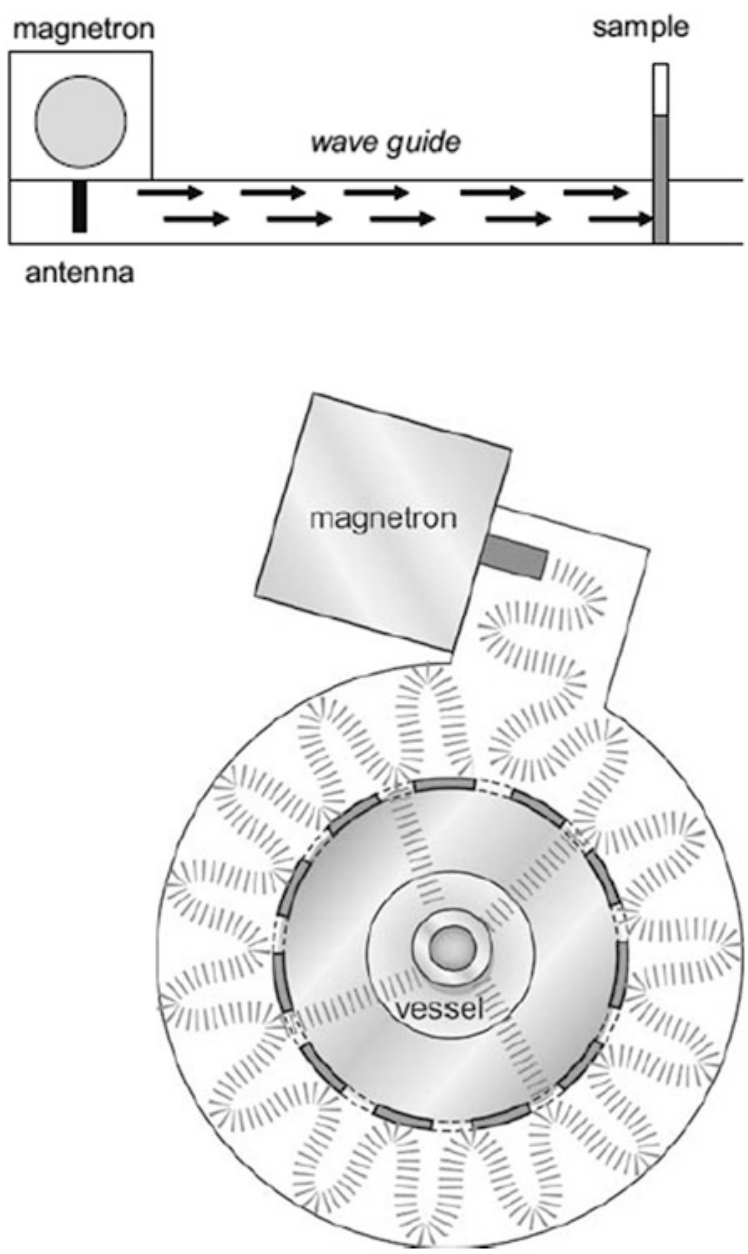

Fig. 1.4 The microwave field distribution in a multimode parallel synthesis reactor [3]

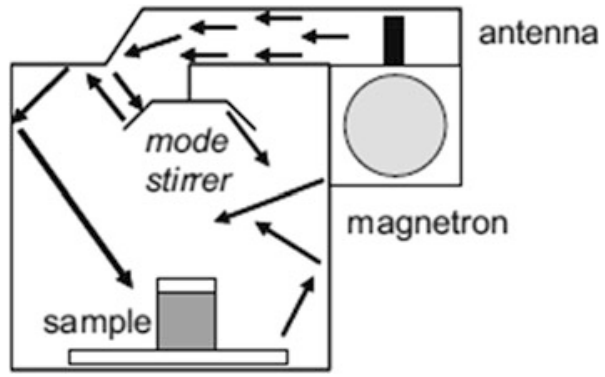


Fig. 1.5 The microwave field magnetron distribution in a multimode single-batch reactor (top view)

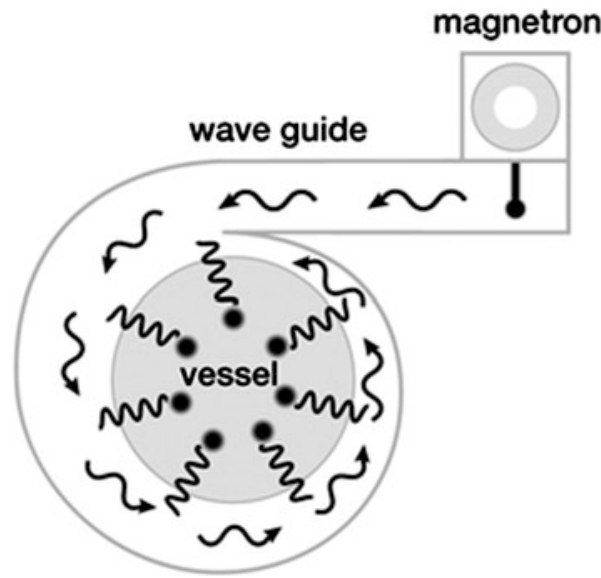

energy distribution. Multimode instruments allow conveniently for parallel syntheses or scale-up. These reactors can host different rotors which are used for parallel reactions in a scale range from several $\mu \mathrm{l}$ up to multi g synthesis in $100 \mathrm{~mL}$ reaction vessels.

There is another type of multimode reactor containing a circular waveguide, where various modes of the electromagnetic waves interact with the vessel content at different spots for efficient heating of larger scales (Fig. 1.5). A single few liter vessel is positioned in the cavity, which provides optimal heating rates for large volumes due to the relatively high field density (compared to common multimode microwave oven shown in Fig. 1.4). This kind of multimode reactor is applied for single-batch scale-up procedure, if up to $2 \mathrm{~kg}$ of product is required.

Special MW reactors are also known, where the microwave is combined with other techniques, such as UV, ultrasound or high pressure systems (e.g. supercritical reactor) [2].

The scale-up of MW-assisted reactions is of specific interest in many industrial laboratories. The safety limitations of using large batch reactors have promoted the development of continuous flow or stopped-flow MW reactors [19, 20]. These reactors usually comprise three parts, such as the dispensing units for the starting reagents, the MW cavity and the product collector (Fig. 1.6). The reagents are pumped using a HPLC pump or even two pumps. The pressure is controlled by a back-pressure regulator, and the temperature is monitored using a fiber optic sensor or a built-in IR sensor. Usually, the reactors are made from Pyrex or Teflon. The efficiency of the continuous flow MW systems can be increased by using parallel reactors.

Nowadays, there are many types of continuous flow MW reactors, which include a normal flask or tube [21], a fixed bed turbular coil [22-24], an $\Omega$ - or U-shaped tube [25-28], a filled column [22, 24, 29] (Fig. 1.7), a spiral glass tube [21, 30-32] (e.g. Emry-type reactor [33] (Fig. 1.8)), a mixed tube [34] (Fig. 1.9) or a capillary reactor [27, 28, 35-37]. 
1 The Spread of the Application of the Microwave Technique ...

(a)

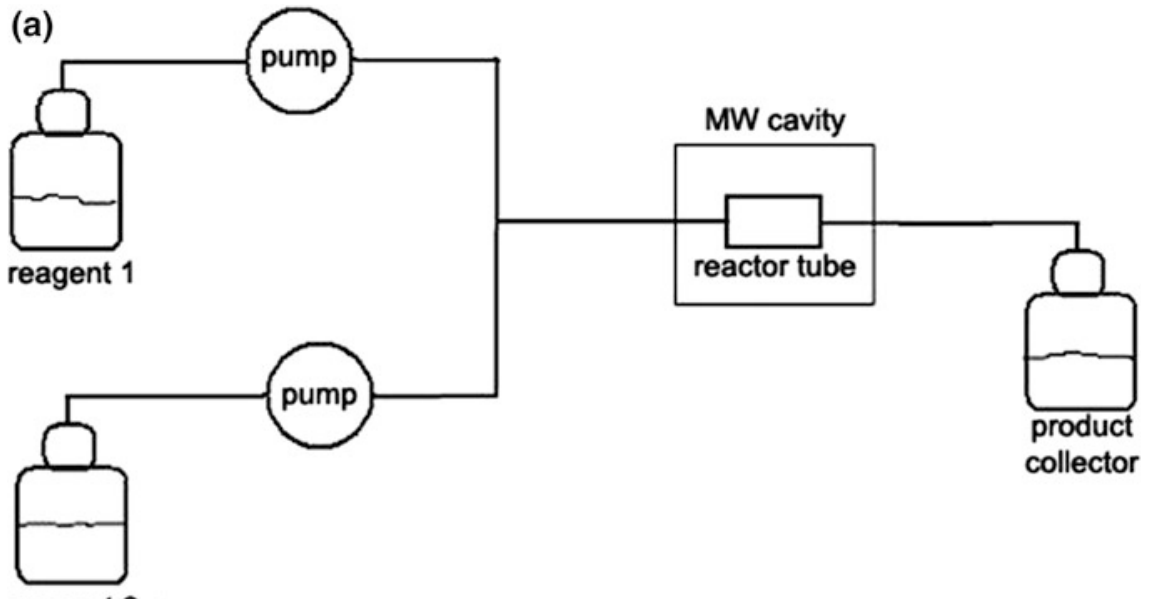

reagent 2

(b)

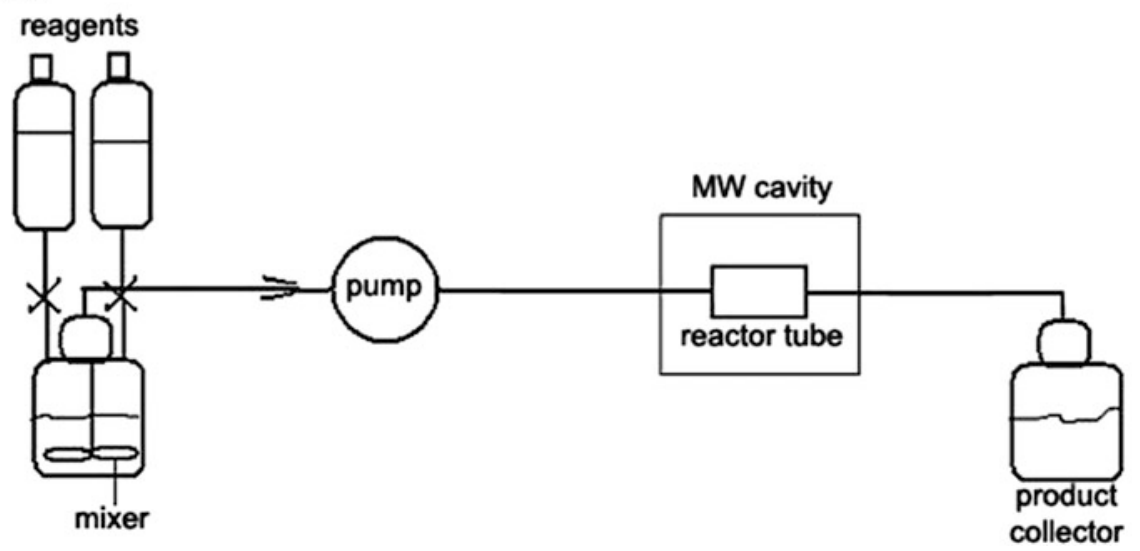

Fig. 1.6 Schematic sketch of continuous flow MW reactors

Fig. 1.7 Filled column

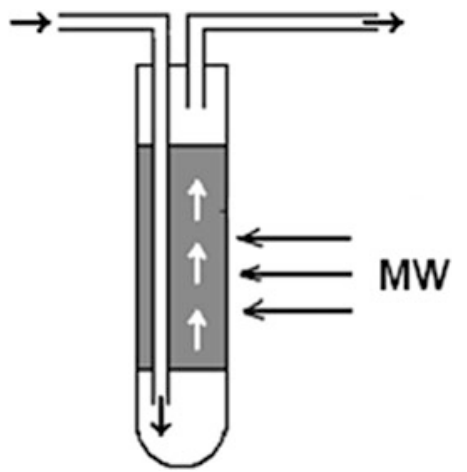




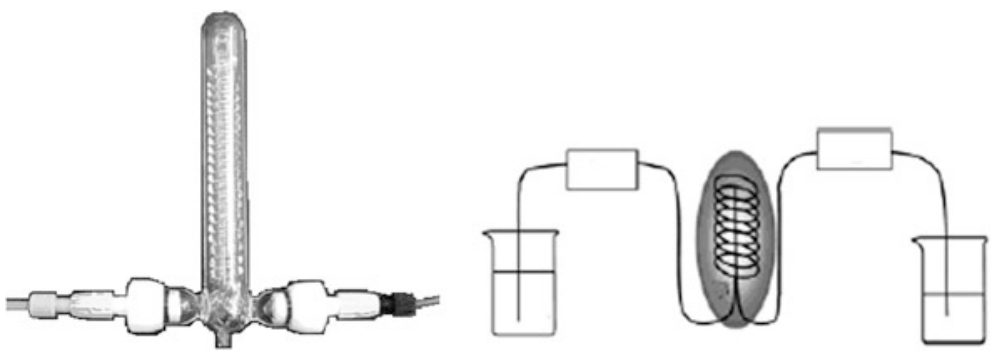

Fig. 1.8 Emry-type reactor

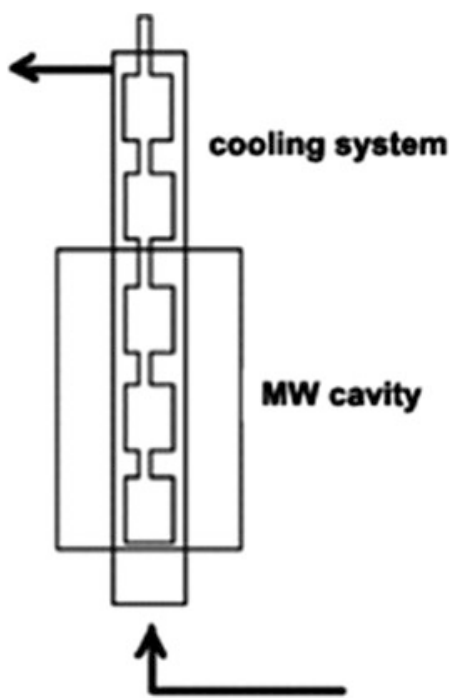

Fig. 1.9 Mixed tube reactor

There is also a continuous equipment to carry out MW-assisted reaction of solid components (Fig. 1.10) [38, 39].

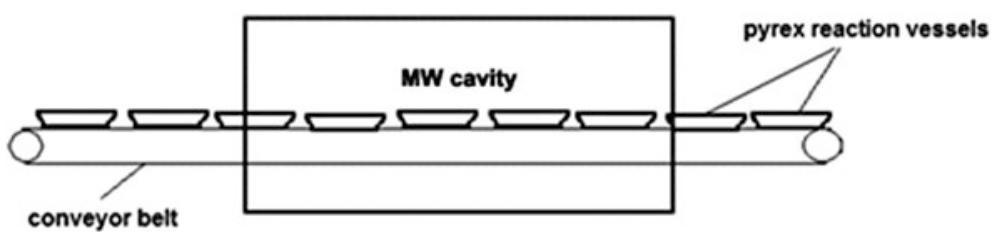

Fig. 1.10 Continuous microwave reactor for solid-phase reaction 
Fig. 1.11 Isothermal MW reactor

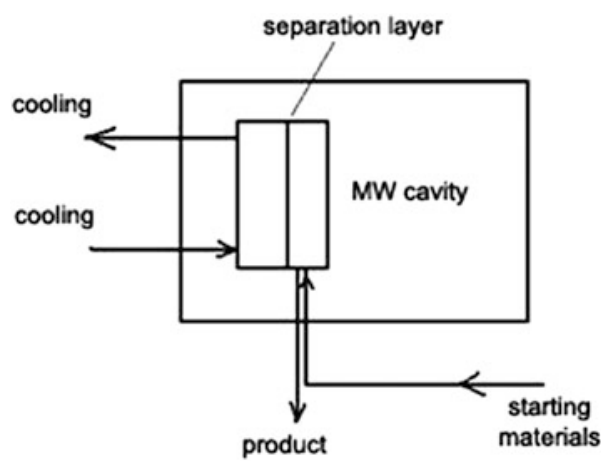

Continuous isothermal MW reactor is also known, which is suitable for implementation of isothermal reactions (Fig. 1.11) [40].

Several MW-assisted continuous flow accomplishments on $\mathrm{g}$ or $\mathrm{kg}$ scale have been reported in the literature [19, 41-54]. Their capacity may reach $500 \mathrm{~kg}$ product per day [55].

\subsection{Conclusions}

In summary, the revolutionary spread of the MW technique resulted in an enormous development in organic chemistry. The appearance of dedicated MW reactors was a "sine qua none" of the new achievements. The mono- and multimode MW batch reactors make possible laboratory scale syntheses, while suitable continuous flow reactors even larger scale production.

\section{References}

1. Anastas PT, Warner JC (1998) Green chemistry: theory and practice. Oxford University Press, New York

2. De La Hoz A, Loupy A (eds) (2012) Microwaves in organic synthesis, vol 1. 3rd edn. Wiley-VCH, Weinheim. doi:10.1002/9783527651313

3. Kappe CO, Stadler A, Dallinger D (2012). In: Mannhold R, Kubinyi H, Folkers G (eds) Microwaves in organic and medicinal chemistry, 2nd edn. Wiley-VCH, Weinheim. doi: $10.1002 / 9783527647828$

4. Ameta SC, Punjabi PB, Ameta R, Ameta C (eds) (2014) Microwave-assisted organic synthesis: a green chemical approach. CRC Press, New York

5. Chemat F, Cravotto G (eds) (2013) Microwave-assisted extraction for bioactive compounds: theory and practice. Food engineering series. Springer, New York. doi:10.1007/978-1-46144830-3

6. Horikoshi S, Serpone N (eds) (2013) Microwaves in nanoparticle synthesis: fundamentals and applications. Wiley-VCH, Weinheim. doi:10.1002/9783527648122 
7. Fang Z, Smith R, Qi X (eds) (2015) Production of biofuels and chemicals with microwave. Biofuels and biorefineries, vol 3. Springer, New York. doi:10.1007/978-94-017-9612-5_1

8. Kempe K, Becer CR, Schubert US (2011) Microwave-assisted polymerizations: recent status and future perspectives. Macromol 44:5825-5842. doi:10.1021/ma2004794

9. Smith FE, Arsenault EA (1996) Microwave-assisted sample preparation in analytical chemistry. Talanta 43:1207-1268. doi:10.1016/0039-9140(96)01882-6

10. Eskilsson SC, Björklund E (2000) Analytical-scale microwave-assisted extraction. J Chromatogr A 902:227-250. doi:10.1016/S0021-9673(00)00921-3

11. Nóbrega JA, Trevizan LC, Araújo GCL, Nogueira ARA (2002) Focused-microwave-assisted strategies for sample preparation. Spectrochim Acta B 57:1855-1876. doi:10.1016/S05848547(02)00172-6

12. Chen L, Song D, Tian Y, Ding L, Yu A, Zhang H (2008) Application of on-line microwave sample-preparation techniques. TrAC-Trend Anal Chem 27:151-159. doi:10.1016/j.trac.2008. 01.003

13. Gedye R, Smith F, Westaway K, Ali H, Baldisera L, Laberge L, Rousell J (1986) The use of microwave ovens for rapid organic synthesis. Tetrahedron Lett 27:279-282. doi:10.1016/ S0040-4039(00)83996-9

14. Giguere RJ, Bray TL, Duncan SM, Majetich G (1986) Application of commercial microwave ovens to organic synthesis. Tetrahedron Lett 27:4945-4948. doi:10.1016/S0040-4039(00) 85103-5

15. Abramovitch RA (1991) Applications of microwave-energy in organic-chemistry. A review Org Prep Proced Int 23:683-711. doi:10.1080/00304949109458244

16. Stadler A, Kappe CO (2000) Microwave-mediated Biginelli reactions revisited. On the nature of rate and yield enhancements. J Chem Soc Perkin Trans 2:1363-1368. doi:10.1039/ b002697m

17. Vidal T, Petit A, Loupy A, Gedye RN (2000) Re-examination of microwave-induced synthesis of phthalimides. Tetrahedron 56:5473-5478. doi:10.1016/S0040-4020(00)00445-2

18. Rinaldi L, Carnaroglio D, Rotolo L, Cravotto G (2015) A microwave-based chemical factory in the lab: from milligram to multigram preparations. J Chem 2015:1-8. doi:10.1155/2015/ 879531

19. Moseley JD (2010) Microwave heating as a tool for process chemistry. In: Leadbeater N (ed) Microwave heating as a tool for sustainable chemistry. CRC Press, New York, pp 105147. doi:10.1002/cssc.201100003

20. Keglevich G, Sallay P, Greiner I (2008) Continuous flow microwave reactors. Hung Chem J 63:278-283

21. Bonaccorsi L, Proverbio E (2008) Influence of process parameters in microwave continuous synthesis of zeolite LTA. Micropor Mesopor Mat 112:481-493. doi:10.1016/j.micromeso. 2007.10.028

22. Bo L, Quan X, Chen S, Zhao H, Zhao Y (2006) Degradation of p-nitrophenol in aqueous solution by microwave assisted oxidation process through a granular activated carbon fixed bed. Water Res 40:3061-3068. doi:10.1016/j.watres.2006.06.030

23. Uy SF, Easteal AJ, Farid MM, Keam RB, Conner GT (2005) Seaweed processing using industrial single-mode cavity microwave heating: a preliminary investigation. Carbohyd Res 340:1357-1364. doi:10.1016/j.carres.2005.02.008

24. Bagley MC, Jenkins RL, Lubinu MC, Mason C, Wood R (2005) A simple continuous flow microwave reactor. J Org Chem 70:7003-7006. doi:10.1021/jo0510235

25. Khadilkar BM, Madyar VR (2001) Scaling up of dihydropyridine ester synthesis by using aqueous hydrotrope solutions in a continuous microwave reactor. Org Process Res Dev 5:452455. doi:10.1021/op010026q

26. Pillai UR, Sahle-Demessie E, Varma RS (2004) Hydrodechlorination of chlorinated benzenes in a continuous microwave reactor. Green Chem 6:295-298. doi:10.1039/b403366c

27. He P, Haswell SJ, Fletcher PDI (2005) Efficiency, monitoring and control of microwave heating within a continuous flow capillary reactor. Sensor Actuat B-Chem 105:516-520. doi:10.1016/j.snb.2004.07.013 
28. He P, Haswell SJ, Fletcher PDI (2004) Microwave-assisted Suzuki reactions in a continuous flow capillary reactor. Appl Catal A-Gen 274:111-114. doi:10.1016/j.apcata.2004.05.042

29. Kabza KG, Chapados BR, Getswicki J, McGrath JL (2000) Microwave-induced esterification using heterogeneous acid catalyst in a low dielectric constant medium. J Org Chem 65:1210 1214. doi: $10.1021 /$ jo $990515 \mathrm{c}$

30. Correa R, Gonzalez G, Dougar V (1998) Emulsion polymerization in a microwave reactor. Polymer 39:1471-1474. doi:10.1016/S0032-3861(97)00413-8

31. Cáceres A, Jaimes M, Chávez G, Bravo B, Ysambertt F, Márquez N (2005) Continuous system with microwave irradiation to obtain alkyl benzoates. Talanta 68:359-364. doi:10. 1016/j.talanta.2005.08.067

32. Cablewski T, Faux AF, Strauss CR (1994) Development and application of a continuous microwave reactor for organic synthesis. J Org Chem 59:3408-3412. doi:10.1021/ jo00091a033

33. Wilson NS, Sarko CR, Roth GP (2004) Development and applications of a practical continuous flow microwave cell. Org Process Res Dev 8:535-538. doi:10.1021/op034181b

34. Bonnet C, Estel L, Ledoux A, Mazari B, Louis A (2004) Study of the thermal repartition in a microwave reactor: application to the nitrobenzene hydrogenation. Chem Eng Proc 43:14351440. doi:10.1016/j.cep.2003.07.003

35. Shore G, Morin S, Organ MG (2006) Catalysis in capillaries by Pd thin films using microwave-assisted continuous-flow organic synthesis (MACOS). Angew Chem Int Ed 45:2761-2766. doi:10.1002/anie.200503600

36. Comer E, Organ MG (2005) A microcapillary system for microwave assisted, high throughput synthesis of molecular libraries. Chem Eur J 11:7223-7227. doi:10.1002/chem.200500820

37. Comer E, Organ MG (2005) A microreactor for microwave-assisted capillary (continuous flow) organic synthesis (MACOS). J Am Chem Soc 127:8160-8167. doi:10.1021/ja0512069

38. Esveld E, Chemat F, van Haveren J (2000) Pilot scale continuous microwave dry-media reactor-Part 1: Design and modeling. Chem Eng Technol 23:279-283. doi:10.1002/(SICI) 1521-4125(200003)23:3<279:AID-CEAT279>3.0.CO;2-P

39. Esveld E, Chemat F, Van Haveren J (2000) Scale continuous microwave dry-media reactorPart II: Application to waxy esters production. Chem Eng Technol 23:429-435. doi:10.1002/ (SICI)1521-4125(200005)23:5<429:AID-CEAT429>3.0.CO;2-T

40. Jachuck RJJ, Selvaraj DK, Varma RS (2006) Process intensification: oxidation of benzyl alcohol using a continuous isothermal reactor under microwave irradiation. Green Chem 8:29_ 33. doi:10.1039/b512732g

41. Singh BK, Kaval N, Tomar S, Eycken EVd, Parmar VS (2008) Transition metal-catalyzed carbon-carbon bond formation Suzuki, Heck, and Sonogashira reactions using microwave and microtechnology. Org Process Res Dev 12:468-474. doi:10.1021/op800047f

42. Baxendale IR, Hayward JJ, Ley SV (2007) Microwave reactions under continuous flow conditions. Comb Chem High Throughput Screen 10:802-836. doi:10.2174/ 138620707783220374

43. Glasnov TN, Kappe CO (2007) Microwave-assisted synthesis under continuous-flow conditions. Macromol Rapid Commun 28:395-410. doi:10.1002/marc.200600665

44. Ullah F, Samarakoon T, Rolfe A, Kurtz RD, Hanson PR, Organ MG (2010) Scaling out by microwave-assisted, continuous flow organic synthesis (MACOS): Multi-gram synthesis of bromo- and fluoro-benzofused sultams benzthiaoxazepine-1,1-dioxides. Chem Eur J 16:10959-10962. doi:10.1002/chem.201001651

45. Dressen MHCL, van de Kruijs BHP, Meuldijk J, Vekemans JAJM, Hulshof LA (2010) Flow processing of microwave-assisted (heterogeneous) organic reactions. Org Process Res Dev 14:351-361. doi:10.1021/op900257f

46. Bergamelli F, Iannelli M, Marafie JA, Moseley JD (2010) A commercial continuous flow microwave reactor evaluated for scale-up. Org Process Res Dev 14:926-930. doi:10.1021/ op100082w 
47. Bagley MC, Fusillo V, Jenkins RL, Lubinu MC, Mason C (2010) Continuous flow processing from microreactors to mesoscale: the Bohlmann-Rahtz cyclodehydration reaction. Org Biomol Chem 8:2245-2251. doi:10.1039/B926387J

48. Moseley JD, Lawton SJ (2007) Initial results from a commercial continuous flow microwave reactor for scale-up. Chem Today 25:6-19

49. Benaskar F, Hessel V, Krtschil U, Löb P, Stark A (2009) Intensification of the capillary-based Kolbe-Schmitt synthesis from resorcinol by reactive ionic liquids, microwave heating or a combination thereof. Org Process Res Dev 13:970-982. doi:10.1021/op9000803

50. Dressen MHCL, van de Kruijs BHP, Meduldijk J, Vekemans JAJM, Hulshof LA (2009) From batch to flow processing: racemization of $\mathrm{N}$-acetylamino acids under microwave heating. Org Process Res Dev 13:888-895. doi:10.1021/op9001356

51. Leadbeater NE, Barnard TM, Stencel LM (2008) Batch and continuous-flow preparation of biodiesel derived from butanol and facilitated by microwave heating. Energy Fuels 22:20052008. doi:10.1021/ef700748t

52. Smith CJ, Iglesias-Siguenza FJ, Baxendale IR, Ley SV (2007) Flow and batch mode focused microwave synthesis of 5-amino-4-cyanopyrazoles and their further conversion to 4-aminopyrazolopyrimidines. Org Biomol Chem 5:2758-2761. doi:10.1039/b709043a

53. Öhrngren P, Fardost A, Russo F, Schanche JS, Fagrell M, Larhed M (2012) Evaluation of a nonresonant microwave applicator for continuous-flow chemistry applications. Org Process Res Dev 16:1053-1063. doi:10.1021/op300003b

54. Organ MG, Hanson PR, Rolfe A, Samarakoon TB, Ullah F (2011) Accessing stereochemically rich sultams via microwave-assisted, continuous flow organic synthesis (MACOS) scale-out. J Flow Chem 1:32-39. doi:10.1556/jfchem.2011.00008

55. Morschhäuser R, Krull M, Kayser C, Boberski C, Bierbaum R, Püschner PA, Glasnov TN, Kappe CO (2012) Microwave-assisted continuous flow synthesis on industrial scale. Green Process Synth 1:281-290. doi:10.1515/gps-2012-0032 